\section{Structure and Nutrition of the Cornea, Cartilage and Wharton's Jelly}

WE have read with great interest the letter by Bareroft et al. ${ }^{1}$. Barcroft and his co-workers observed the passage of large molecules in Wharton's jelly of the umbilical cord of fotal sheep, and they believe that there exists a non-vascular pathway through which nourishment travels along from the placenta towards the foetus. While there seems to be every justification for this interpretation of the findings, we are of the opinion that this easy and relatively fast passage of large molecules may contribute to the nutrition of Wharton's jelly itself. With a few exceptions ${ }^{2}$ (apart from the large umbilical vessels, which are not supposed to give off nourishment for the surrounding tissues) the substance of the umbilical cord is completely avascular. In this respect Wharton's jelly is closely similar to cartilage and the cornea. It is generally accepted that both cartilage and the cornea are nourished by diffusion from the surrounding tissues, and it seems to us that to assume a similar method of nourishment for Wharton's jelly is entirely justifiable. Both Wharton's jelly and cartilage are rich in two closely related substances, mucoitin sulphuric acid and chondroitin sulphuric acid respectively.

Some months ago our attention was directed to the work of Jorpes et $a l .^{3}$ describing the presence of heparin in the substantia propria of the human and bovine cornea. This observation was based on the metachromatic staining reaction of the substantia propria corneæ after toluidin-blue staining. We repeated this method on sections of rabbit, guinea pig, rat and normal human cornex, and we confirmed the presence of a metachromatic substance. The reaction in the rabbit's cornea, especially after the use of basic lead acetate as a fixing agent, was particularly intense. This staining reaction is strictly confined to the cornea and stops sharply at the corneo-scleral junction. While the real chemical basis of this reaction can be proved only by microchemical analysis, it appears justifiable to suppose that the substance responsible for the specific staining reaction is either heparin, which is a mucoitin polysulphuric acid, or a chemically allied substance, because only these substances give a metachromatic staining reaction with toluidin-blue.

The presence of metachromatic substances in the substantia propria corneæ is not given in standard histological descriptions, although muco-protein was found by Mörner ${ }^{4}$ and mucoitin sulphuric acid by Leven $\theta^{5}$ after chemical analysis. Krause ${ }^{6}$ in his book on the biochemistry of the eye, referring to the above findings, states that the part played by these acids in such "metabolically inactive" tissue as the substantia propria is not known.

It is of interest that the mast cells, which, according to Jorpes et al. ${ }^{3}$ are responsible for the production and the maintenance of the heparin level of the circulation, give a particularly vigorous metachromatic staining, and consequently the intensity of metachromasia displayed by these chemically related substances can be used within certain limits as a starting point for chemical differentiation.

As previously stated, the cornea derives its main nutrition by diffusion from the margin. We have found numerous mast cells around the capillary loops at the limbus cornex, and we believe that these cells facilitate diffusion and nutrition by maintaining a high heparin concentration. The translucency of the cornea may also be maintained by and dependent upon the presence of heparin, or some chemically related substance.

The cornea, cartilage and Wharton's jelly are avascular structures, and they all contain similar or closely related metachromatic substances. They all bear the same peculiar relationship to their blood supply, and consequently their nutrition must be similar. Our assumption gains support from the findings of Barcroft et al. ${ }^{1}$.

Finally, it is significant that the cornea is the only tissue with which successful homografting can be carried out, and the explanation may lie in its chemical structure and peculiar nutritional conditions.

Department of Anatomy and

PAUL BACSICH.

W. J. B. RIDDELL.

Department of Ophthalmology,

University of Glasgow.

Jan. 17.

${ }^{1}$ Barcroft, J., Danielli, J. F., Harper, W. F., and Mitchell, P. D., Nature, 154, 667 (1944).

${ }^{2}$ Barclay, A. E., Franklin, K. J., and Prichard, M. M. L., "The Fœtal Circulation" (Oxford, 1944).

${ }^{3}$ Jorpes, J. E., Holmgren, H., and Wilander, O., Z. Mikrosk.-anat. Forsch., 42, 279 (1937).

${ }^{4}$ Mörner (quoted by Krause)

${ }^{5}$ Levene (quoted by Krause).

"Krause, A. C., "The Biochemistry of the Eye" (Baltimore, 1934).

\section{Mechanism of Bacterial Flocculation caused by Protozoa}

WITHIN the last two or three years several investigators $^{1-4}$ have reported in these columns that certain Protozoa growing in sewage possess the power of causing flocculation of the bacteria on which they feed, a property which is obviously of value to the organisms themselves, since it facilitates the collection of food bacteria, and may also be of importance in sewage purification.

So far as I am aware, the mechanism of this peculiar phenomenon has not been described. In the holotrichous ciliate Balantiophorus minutus, the ability of which to cause such flocculation has already been recorded ${ }^{5}$, it has been found that the feeding mechanism involves the production of mucus, secreted within the peristome, to which the food bacteria adhere before being ingested, and are thus prevented from being swept out of the peristome by the ciliary currents. This mucus has been found gradually to accumulate in the culture-fluid and, not being a diffusible substance, remains in the neighbourhood of the ciliates themselves. The resulting local increase in the viscosity of the culture medium causes the entanglement and flocculation of the bacteria. When floccula from Balantiophorus minutus cultures are examined under the microscope, the bacteria are seen to be cemented together by an amorphous substance which, upon staining with methylene blue, with mucicarmine and Delafield's hæmatoxylin, or with safranin, shows the metachromatic effect characteristic of mucin with these dyes. Control cultures of the same mixed bacterial flora which have not been inoculated with the ciliate show no flocculation; and smears, upon staining, give sharp monochromatic coloration, no matrix being visible between the bacteria. 